\title{
PERENCANAAN MEDIA PEMBELAJARAN SAMBUNGAN DAN HUBUNGAN KAYU BERBASIS TIK PADA MATA PELAJARAN PRODUKTIF TEKNIK FURNITUR
}

\author{
Abu Bakar Ranto, Arris Maulana, Risdian M Noor
}

\begin{abstract}
This innovative work undertaken in order to improve the quality of student learning outcomes and create new experiences for learners in learning process for the course of Furniture Construction especially for the subject of Timber Connection and Assembling. This innovative work was tested at SMK Negeri 52 Jakarta.

The method of this innovative work is done based on seven stages. Those seven stages are observation (data collective), preparation of materials, information flow preparation, data compilation, initial development, evaluation and ending development. Evaluation process carried out by two phases, validation and revision. Validation phase was conducted by media expertise from the Center for Learning Resources (PSB) and for the content and instructional expertise conducted by two teachers for the course of Furniture Construction especially for the subject of Timber Connection and Assembling in SMK Negeri 52 Jakarta.

From the calculation of the media expertise, we get the average of 4.5 total validations. It indicates that the media; if we viewed from the range $4.5 \leq x$ $\leq 5$; is accepted into the criteria of excellent value. From the calculation and validation of instructional substance expertise, we obtained the average total validation of 4.425 . If we analyze from the range $3.5 \leq x<4.5$, then the value is accepted into the good criterion. Learning outcomes from students in class $X$ TF B SMK Negeri 52 Jakarta using this method showed an increasing value by the average of 76.23 from the scale of 1-100 on the Basic Competency-8, Timber Connection and Assembling.
\end{abstract}

Keywords : innovative work, learning outcomes

\begin{tabular}{|l|c|r|}
\hline $\begin{array}{l}\text { Abu Bakar Ranto } \\
\text { Alumni Jurusan Teknik Sipil }\end{array}$ & Drs. Arris Maulana, MT & Drs. Risdian M Noor, MP.d \\
Fakultas Teknik & Jurusan Teknik Sipil & Jurusan Teknik Sipil \\
Universitas Negeri Jakarta, 13220 & Fakultas Teknik & Fakultas Teknik \\
& $\begin{array}{c}\text { Universitas Negeri Jakarta, 13220 } \\
\text { email: t_iriani@yahoo.com }\end{array}$ & $\begin{array}{c}\text { Universitas Negeri Jakarta, 13220 } \\
\text { email:arrismaulana@yahoo.co.id }\end{array}$ \\
\hline
\end{tabular}




\section{PENDAHULUAN}

Pada awalnya kayu hanya digunakan sebagai bahan bakar untuk memasak saja. Pada perkembangannya kayu juga digunakan untuk membuat konstruksi sebuah bangunan dan juga dimanfaatkan untuk kegunaan mebel. Untuk kegunaan mebel bahan ini sangat aman dan mudah untuk dibentuk. Kayu dibentuk menjadi bagian-bagian komponen lalu dirakit, dengan menggunakan penyambung atau dengan bantuan alat perekat, akhirnya jadilah sebuah perabot-perabot rumah tangga.

Sambungan kayu umumnya hanya menggabungkan dua buah kayu atau lebih. Namun seiring berkembangnya teknologi, sambungan kayu mengalami beberapa penambahan, baik itu sambungan dengan paku, baut, dan juga dengan plat besi. Sekolah Menengah Kejuruan khususnya pada bidang keahlian perabot kayu atau teknik furnitur mempelajari banyak hal mengenai hal tersebut, mulai dari pembahanan sampai dengan finishing.

Metode ceramah memang sudah biasa diterapkan pada saat kegiatan belajar mengajar. Metode konvensional ini memiliki syarat yang harus dipenuhi agar siswa dapat mengerti apa yang ingin disampaikan oleh seorang pendidik. Banyak pendidik yang menggunakan metode ini, namun banyak juga siswa yang jenuh serta materi yang disampaikan kurang mengena dan terkadang tidak efektif.

Dari nilai hasil belajar siswa di SMK Negeri 52 Jakarta Tahun Ajaran 2009/2010 pada Mata Pelajaran Produktif Sambungan dan Hubungan Kayu didapat nilai rata-rata siswa sebesar 81,9. Namun, pada Tahun Ajaran 2010/2011 nilai hasil belajar siswa menurun menjadi 79,5. Untuk meningkatkan kembali hasil belajar siswa perlu dibuat sebuah inovasi dalam penyampaian materi. Pendidik harus melakukan perubahan dalam metode mengajar, serta memanfaatkan media pendukung dalam proses pembelajaran. Sehingga dapat membuat siswa menjadi lebih tertarik dan semangat untuk belajar karena adanya inovasi baru dalam metode belajar-mengajar.

Azhar Arsyad (2011) menyatakan bahwa dalam suatu proses belajar mengajar, dua unsur yang amat penting adalah metode mengajar dan media pembelajaran. Kedua aspek ini saling berkaitan. Media merupakan bagian yang tidak terpisahkan dari proses belajar mengajar demi tercapainya tujuan pendidikan. Pemilihan salah satu metode mengajar tentu akan mempengaruhi jenis media pembelajaran yang sesuai. Pemilihan media pembelajaran juga dilihat dari sifat tugas pembelajaran serta isi pelajaran. Media pembelajaran ini berbasis teknologi informasi dan komunikasi, berupa pemaparan bentuk 3 dimensi, video bergerak, audio, dan materi yang mendukung kegiatan belajar, serta soal-soal latihan.

Mulyanta (2008) menyatakan berbagai faktor yang menyebabkan kurang optimalnya hasil belajar terkait dengan pengembangan media pembelajaran. Yaitu: pendidik tidak tahu cara menggunakan media pembelajaran dalam proses pembelajaran, penggunaan media pembelajaran oleh pendidik sangat terbatas dan tidak substantif sehingga dirasakan kurang membantu dalam penguasaan bahan ajar serta kurang variatifnya media pembelajaran sehingga pembelajar sangat membosankan.

Pembuatan media pembelajaran berbasis teknologi informasi dan komunikasi ini diharapkan dapat membantu pendidik dalam menyampaikan materi dan membantu siswa dalam menerima materi. 
Pemakaian media pembelajaran dalam proses belajar mengajar dapat meningkatkan keinginan dan minat yang baru, membangkitkan motivasi dan rangsangan kegiatan belajar, dan bahkan membawa pengaruh psikologis terhadap siswa.

\section{Media Pembelajaran}

Secara etimologis, media berasal dari bahasa Latin, merupakan bentuk jamak dari kata "medium" yang berarti "tengah, perantara, atau pengantar". Dalam bahasa Arab media adalah perantara (wasa- i) atau pengantar pesan dari pengirim kepada penerima pesan. Menurut Bovee (dalam Arsyad, 2011) fungsi media adalah sebagai perantara atau pengantar suatu pesan dari si pengirim (sender) kepada si penerima (receiver) pesan. The Association for Education Communication and Technology (AECT, 1977) menyatakan bahwa media adalah apa saja yang digunakan untuk menyalurkan informasi.

Pada mulanya media hanya dianggap sebagai alat bantu mengajar. Alat bantu yang dipakai adalah alat bantu visual, misalnya gambar, model, objek dan alat-alat lain yang dapat memberikan pengalaman konkret, motivasi belajar serta mempertinggi daya serap dan retensi belajar siswa (Arief, 2009). Berkembangnya informasi, media tidak lagi hanya dipandang sebagai alat bantu belaka bagi guru untuk mengajar, tetapi lebih sebagai alat penyalur pesan dari pemberi pesan (guru, penulis buku, dan sebagainya) ke penerima pesan (siswa/peserta didik).

Menurut Hamalik (2005) media pembelajaran adalah suatu bagian integral dari proses pendidikan di sekolah karena itu menjadi suatu bidang yang harus dikuasai oleh setiap guru professional. Bidang ini telah berkembang sedemikian rupa berkat kemajuan ilmu, teknologi dan perubahan sikap masyarakat sehingga media pembelajaran mempunyai fungsi yang lebih luas serta memiliki nilai yang sangat penting dalam dunia pendidikan di sekolah. Jadi, yang dimaksud dengan media pembelajaran adalah alat, metode, dan teknik yang digunakan dalam rangka lebih mengefektifkan komunikasi dan interaksi antara guru dan siswa dalam proses pembelajaran di sekolah.

Menurut Arief (2009) media pembelajaran sebagai salah satu sumber belajar yang dapat menyalurkan pesan sehingga membantu mengatasi kekurangan dalam pembelajaran. Kekurangan yang dimaksud misalnya adalah perbedaan gaya belajar, minat, intelegensi, keterbatasan daya indera, cacat tubuh atau hambatan geografis, jarak, waktu dan sebagainya. Semua factor kekurangan tersebut dapat diatasi dengan pemanfaatan media pembelajaran.

Kata pembelajaran merupakan terjemahan dari istilah Bahasa Inggris, yaitu "instruction". Instruction diartikan sebagai proses interaktif antara guru dan siswa yang berlangsung secara dinamis. Tugas guru dalam proses pembelajaran, disamping menyampaikan informasi, ia juga bertugas mendiagnosis kesulitan belajar siswa, menyeleksi materi ajar, mensupervisi kegiatan belajar, menstimulasi kegiatan belajar siswa, memberikan bimbingan belajar, mengembangkan dan menggunakan strategi dan metode (Saputro,1996).

Setelah memahami kata "media" dan "pembelajar" secara terpisah, maka dengan menggabungkan 
kedua istilah itu pengertian "media pembelajaran" adalah apabila media itu membawa pesan-pesan atau informasi yang bertujuan instruksional atau mengandung maksud-maksud pengajaran maka media itu disebut media pembelajaran.

Penggunaan komputer sebagai media pembelajaran dikenal dengan nama Pembelajaran dengan Bantuan Komputer (Computer-Assisted Instruction - CAl, atau Computer-Assisted Learning CAL). Dilihat dari situasi belajar dimana komputer digunakan untuk tujuan menyajikan isi pelajaran, CAI bisa berbentuk tutorial, drills and practice, simulasi, dan permainan (Arsyad, 2011) .

Karena keterbatasan panjang kayu yang ada di perdagangan maka untuk suatu konstruksi kayu yang panjang diperlukan adanya sambungan kayu. Pengertian sambungan kayu adalah dua batang kayu atau lebih yang saling disambungkan satu sama lain sehingga menjadi satu batang kayu yang panjang. Pengertian hubungan kayu adalah dua batang kayu atau lebih yang saling dihubungkan satu sama lain pada satu titik tertentu sehingga menjadi satu bagian konstruksi (Daryanto, 2010).

Teknologi Informasi dan Komunikasi (TIK) dalam sudut pandang pendidikan merujuk pada TIK seperti perkomputeran, fasilitas komunikasi, dan fitur-fitur yang bervariasi untuk mendukung pengajaran, pembelajaran, dan berbagai aktivitas pendidikan. QCA Scheme of Work for ICT dalam Hartoyo, 2012 menyatakan: istilah TIK terdiri dari tiga huruf yang berbeda tetapi merupakan komponen yang memiliki makna erat.

Pembelajaran berbasis produk merupakan interaksi antara guru dan peserta didik dari kegiatan belajar mengajar yang mengacu pada proses produksi untuk mencapai standar kompetensi dan kompetensi dasar tertentu. Pendekatan ini akan memiliki muatan ganda, yaitu keterampilan dan menghasilkan komoditijasa maupun produk. Ini yang diarahkan untuk mengisi kebutuhan pasar dan penjual (Kurikulum SMKN 52 Jakarta, 2011).

Mata pelajaran produktif adalah pembelajaran kejuruan yang merupakan kemampuan khusus yang diberikan kepada siswa sesuai dengan program keahlian yang dipilihnya. Pembelajaran berbasis produk diberikan di bengkel/instalasi masing-masing jurusan. Untuk mengefektifkan proses pembelajatan berbasis produk, dilakukan secara sistem ganda. Tujuanya diharapkan dapat meningkatkan kemampuan keterampilan dan kompetensi siswa pada keahlian tertentu agar dapat digunakan untuk bersaing di dunia usaha dan industri.

Penggunaan media pembelajaran dapat menambah kemenarikan tampilan materi sehingga meningkatkan motivasi dan minat serta mengambil perhatian peserta didik untuk fokus mengikuti materi yang disajikan, sehingga diharapkan efektivitas belajar akan meningkat pula. Media pembelajaran juga dapat merangsang peserta didik untuk berfikir kritis, menggunakan kemampuan imajinasinya, bersikap dan berkembang lebih lanjut, sehingga melahirkan kreativitas dan karya-karya inovatif. Berdasarkan kemampuan media dalam mempengaruhi berbagai macam isi pembelajaran, media pembelajaran yang sangat besar manfaatnya adalah film. 
Media yang cocok untuk digunakan dalam kegiatan belajar mengajar pada tingkat SMK yang mana lebih mengedepankan keterampilan, prosedur pekerjaan, dan memerlukan peralatan teknis, adalah media dalam bentuk slide, film dan simulasi. Untuk itu media pembelajaran yang akan dibuat dalam bentuk slide materi, yang didalamnya terdapat video demonstrasi, animasi 3D, dan perspektif gambar kerja dalam bentuk 3D. Materi yangakan dibuat berdasarkan dengan silabus dan kurikulum.

\section{METODE}

Materi pembelajaran dalam media pembelajaran yang akan dibuat hanya menyangkut Mata Pelajaran Sambungan dan Hubungan Kayu (KF 4) Kelas X Semester 2 SMKN 52 Jakarta Teknik Furnitur. Pokok Bahasan pada mata pelajaran ini meliputi kemampuan satu standar kompetensi dan delapan kompetensi dasar. Keterangan detail dapat dilihat pada Tabel 1 dan pelaksanaan penelitian dilakukan seperti yang ditampilkan bagan alur pada Gambar 1.

Tabel 1. Standar Kompetensi dan Kompetensi Dasar

\begin{tabular}{|l|l|}
\hline \multicolumn{1}{|c|}{ STANDAR KOMPETENSI } & \multicolumn{1}{c|}{ KOMPETENSI DASAR } \\
\hline Membuat sambungan dan & 1. Mendeskripsikan pembuatan sambungan \\
hubungan kayu untuk pekerjaan & \multicolumn{1}{c|}{ dan hubungan kayu } \\
mebel/furniture & 2. Menetapkan melukis pekerjaan kayu \\
& 3. Memotong kayu \\
& 4. Membelah kayu \\
& 5. Mengetam kayu \\
& 6. Membuat sambungan kayu \\
& 7. Membuat hubungan kayu \\
& 8. Merakit sambungan dan hubungan kayu \\
\hline
\end{tabular}

Sumber : Silabus SMK Negeri 52 Jakarta, 2010

Materi bahasan pada intinya mengenai membuat sambungan dan hubungan kayu untuk pekerjaan mebel/furniture. Materi ini terdiri dari: mendeskripsikan pembuatan sambungan dan hubungan kayu; menetapkan melukis pekerjaan kayu; memotong kayu; membelah kayu; mengetam kayu; membuat sambungan kayu; membuat hubungan kayu; merakit sambungan dan hubungan kayu.Validasi media pembelajaran yang dibuat, meliputi validasi program dan diuji pengaruhnya terhadap prestasi hasil belajar siswa. Sedangkan bentuk interaksi melalui komputer yang akan dibuat merupakan bentuk pemaparan , yaitu penyajian informasi dan pengetahuan dalam bentuk video demonstrasi, dan penyajian job sheet dalam bentuk 3D serta diakhiri dengan latihan soal.

Validasi ahli media dilaksanakan oleh Bapak Drs. Mochtar M. Noor, M.Pd sebagai ahli media yang disaranakan oleh Pusat Sumber Belajar Universitas Negeri Jakarta. Beliau berprofesi sebagai Dosen Teknologi Pendidikan Fakultas IImu Pendidikan Universitas Negeri Jakarta. Beliau juga merupakan ahli media dari Pusat Sumber Belajar (PSB) Universitas Negeri Jakarta. 


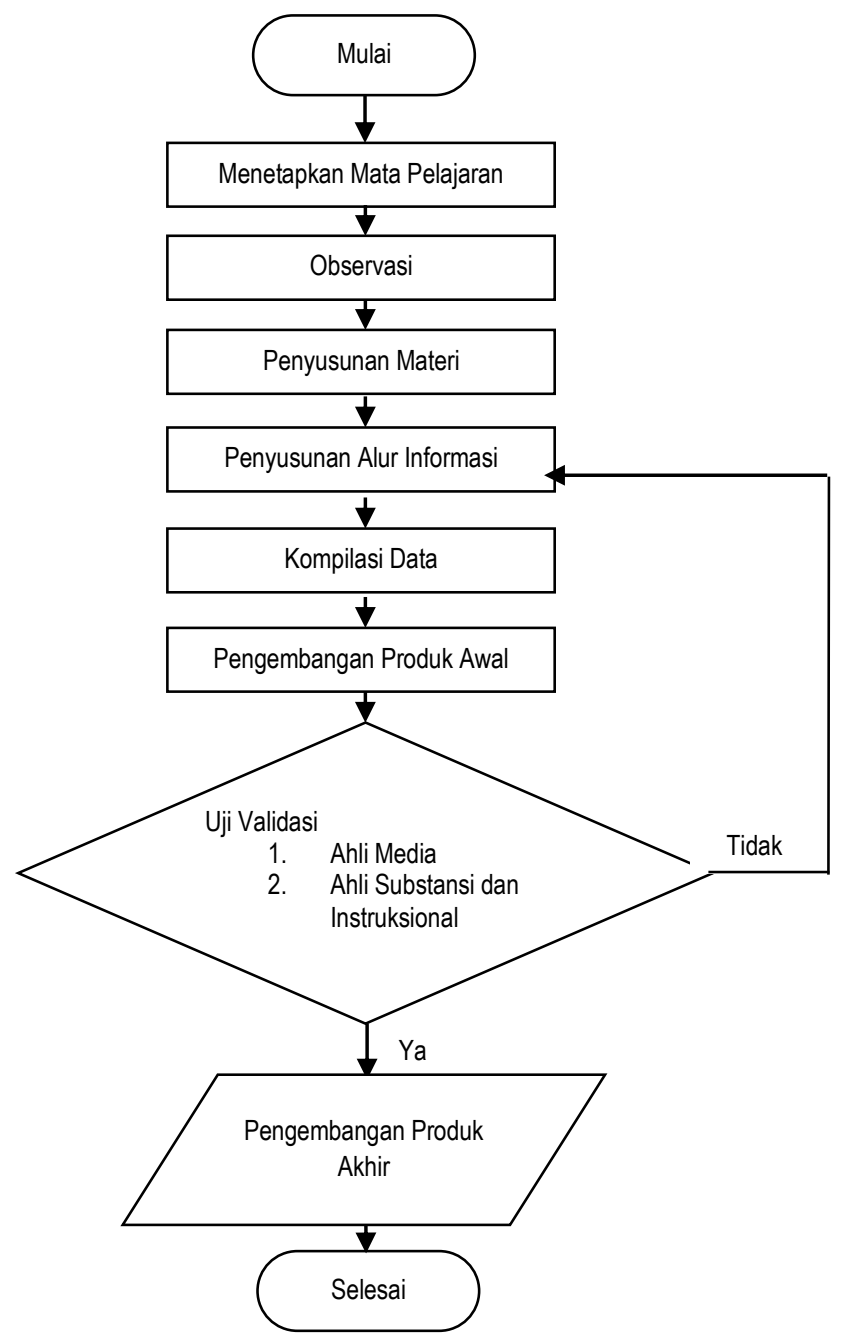

Gambar 1. Diagram Alir Strategi dan Perancangan

Validasi ahli substansi dan instruksional dilaksanakan oleh Bapak Drs. Suwarno (ahli substansi dan instruksional 1) dan Ibu Dra. Hj. Siti Osfan Husein (ahli substansi dan instruksional 2). Bapak Drs. Suwarno berprofesi sebagai Guru Mata Pelajaran Produktif dan menjabat sebagai Ketua Jurusan Teknik Furnitur di SMKN 52 Jakarta, Jalan Taruna Jaya, Ciracas, Cibubur, Jakarta Timur. Ibu Dra. Hj. Siti Osfan Husein berprofesi sebagai Guru Mata Pelajaran Produktif di SMKN 52 Jakarta, Jalan Taruna Jaya, Ciracas, Cibubur, Jakarta Timur.

\section{HASIL DAN PEMBAHASAN}

Dari hasil perhitungan, didapat rata-rata total validasi ahli media adalah 4,5 . Jika dilihat dari range $4,5 \leq x$ $\leq 5$, maka nilai tersebut masuk kedalam kriteria nilai sangat baik. Selain itu, dari review ahli media didapati catatan yaitu gambar pada saat praktek sebaiknya ada gambar dengan pengambilan close up (diperbesar objeknya) supaya lebih jelas. 
Sedangkan hasil perhitungan validasi ahli substansi dan instruksional didapatkan rata-rata total sebesar 4,425. Jika dilihat dari range $3,5 \leq x<4,5$, maka nilai tersebut masuk kedalam kriteria nilai baik. Selain itu, dari review ahli substansi dan instruksional pembelajaran didapati banyak catatan, yaitu :

1. Sambungan bibir lurus ukuran kayu harus nyata (berapa) untuk mengetahui panjang sambungan

2. Posisi balok pada sambungan bibir lurus harus diubah karena salah

3. Untuk judul gambar kerja harus diperbaiki yaitu sambungan bibir lurus (bukan detail)

4. Pada sambungan sudut pada gambar proyeksi miring kurang menunjukkan gambar yang jelas sehingga orang yang mengerjakan atau melihat detail

5. Dibuat soal pertanyaan awal dan pertanyaan akhir dengan ukuran benda kerja yang jelas

6. Terdapat istilah yang tidak perlu digunakan

7. Pada gambar sambungan diperjelas dengan ukuran dan tampak dari sambungan tersebut

8. Pada saat diperlihatkan materi harus diulang beberapa kali dan selingi dengan musik agar siswa bersemangat

\section{Uji Media Terhadap Hasil Belajar Siswa}

Uji media dilaksanakan di SMKN 52 Jakarta pada Kelas X Teknik Furnitur B, dengan memberikan materi belajar mengunakan media pembelajaran sambungan dan hubungan kayu. Sedangkan untuk pembandingnya yaitu Kelas X Teknik Furnitur A kegiatan belajar mengajar tidak menggunakan media pembelajaran sambungan dan hubungan kayu. Diujikan pada Kompetensi Dasar ke-8, Merakit Sambungan Kayu, dan didapat nilai rata-rata kelas X TF B yaitu 76,23 dari skala 1-100 dan nilai rata-rata kelas X TF A yaitu 75 dari skala 1-100, dengan nilai KKM (Ketuntasan Kriteria Minimum) 70 dari skala 1100. Terdapat perbedaan dalam nilai rata-rata hasil belajar menggunakan media pembelajaran sambungan dan hubungan kayu. Nilai rata-rata hasil belajar pada kelas X TF B lebih baik dibandingkan dengan nilai rata-rata hasil belajar kelas X TF A.

Hal ini membuktikan bahwa media pembelajaran sambungan dan hubungan kayu layak digunakan karena hasil belajar yang menggunakan media pembelajaran lebih tinggi dibandingkan dengan kegiatan hasil belajar yang tidak menggunakan media pembelajaran. Walaupun perbedaannya tidak terlalu jauh, namun sudah dapat terlihat bahwa sistem pembelajaran dengan menggunakan media lebih dapat menarik minat siswa untuk memperhatikan dan menanyakan hal-hal yang sedang dipelajari. Karena dengan menggunakan media pembelajaran, siswa dapat langsung melihat praktik dari materi yang sedang diajarkan. Sehingga pada saat siswa melakukan praktik untuk menguji pemahaman terhadap materi yang sedang dipelajari, siswa tidak lagi banyak bertanya sehingga lebih efektif.

Hasil belajar kelas X TF B yang menggunakan media pembelajaran memang relatif lebih baik jika dibandingkan dengan hasil belajar kelas X TF A yang tidak menggunakan media pembelajaran. Namun, jika dibandingkan dengan hasil belajar tahun ajaran 2010/2011 nilai hasil belajar kelas X di SMKN 52 Jakarta sebesar 79,5 dan nilai hasil belajar kelas X TF B di SMKN 52 Jakarta tahun 2011/2012 sebesar 
76,23; maka, hasil belajar tahun ajaran 2011/2012 tidak lebih baik dari hasil belajar tahun ajaran 2010/2011. Hal ini dikarenakan terdapat beberapa kendala dalam melakukan kegiatan belajar mengajar, yaitu:

1. Perlu adanya penyesuaian dalam menggunakan media pembelajaran dalam kegiatan belajar mengajar.

2. Siswa lebih memilih untuk meminta softcopy materi daripada mencatat dalam buku catatan

3. Dibutuhkan waktu untuk meningkatkan hasil belajar siswa, tidak bisa langsung meningkat saat itu juga.

4. Kurangnya sarana dan prasarana pada saat kegiatan belajar mengajar.

\section{KESIMPULAN}

Kesimpulan yang dapat diambil dari pembuatan media pembelajaran sambungan dan hubungan kayu adalah sebagai berikut:

1. Prosedur pengembangan media pembelajaran yang telah dihasilkan media pembelajaran melalui 7 tahap yaitu, observasi (pengumpulan data), penyusunan materi, penyusunan alur informasi, kompilasi data, pengembangan awal, evaluasi dan pengembangan akhir.

2. Dengan adanya karya inovatif ini, menunjukkan bahwa program-program komputer dapat digunakan untuk membuat media pembelajaran yang interaktif dalam dunia pendidikan. Sehingga akan menumbuhkan motivasi para pendidik untuk membuat media pembelajaran yang lebih variatif dan inovatif.

3. Dari hasil penelitian, media pembelajaran yang dibuat cukup layak untuk digunakan sebagai alat bantu guru dalam mengajar dikela karena terjadi peningkatan hasil belajar peserta didik. Hal ini ditunjukkan dari hasil validasi ahli media yaitu 4,5 dari skala 1-5, validasi ahli substansi dan instruksional yaitu 4,425 dari skala 1-5, dan hasil belajar siswa Kelas X di SMKN 52 Jakarta yang menunjukkan peningkatan nilai dengan rata-rata 76,23 dari skala 1-100, pada Kompetensi Dasar merakit sambungan dan hubungan kayu.

4. Karya inovatif ini dapat dijadikan salah satu alternatif dalam media pembelajaran yang lebih praktis, efektif dan efisien.

\section{DAFTAR PUSTAKA}

Arsyad, Azhar. 2011. Media Pembelajaran. Jakarta: Rajawali Press.

Asyhar, Rayandra. 2011. Kreatif Mengembangkan Media Pembelajaran. Jakarta: Gaung Persada Press.

Chandra, Handi. 2011. Google SketchUp 8 untuk Orang Awam. Jakarta: Maxikom.

Daryanto. 2010. Ketrampilan Kejuruan Konstruksi Kayu. Bandung: Satu Nusa.

Hamalik, Oemar. 2005. Media Pendidikan. Bandung: Citra Aditya Bakti. 
Hartoyo. 2012. Teknologi Informasi dan Komputer dalam Pembelajaran Bahasa. Semarang: Pelita Insani Semarang.

Hendratman, Hendi. 2011. The Magic of Macromedia Director. Bandung: Informatika.

Martono, Budi. 2008. Teknik Perkayuan Jilid I. Jakarta: Direktorat Pembinaan Sekolah Menengah Kejuruan, Kementrian Pendidikan Nasional.

Mulyanta. 2009. Tutorial Membangun Multimedia Interaktif Media Pembelajaran. Yogyakarta: Penerbit Universitas Atmajaya Yogyakarta.

Sadiman, Arief. 2009. Media Pendidikan: Pengertian, Pengembangan, dan Pemanfaatannnya. Jakarta: Rajawali Press

Silabus SMK Negeri 52 Jakarta 2011

Simarmata, Janner. 2006. Pengenalan Teknologi Komputer dan Informasi. Yogyakarta: Penerbit ANDI.

Steiger, Ludwig. 2010. Basics Timber Construction (Penerjemah Agus Tiono). Jakarta: Erlangga.

Sudjana, Nana. 2011. Penilaian Hasil Belajar Mengajar. Bandung: PT. Remaja Rosdakarya.

Taniredja, tukiran. 2011. Penelitian Kuantitatif (Sebuah Pengantar). Bandung: Alfabeta.

Wahab Rosyidi, Abdul. 2009. Media Pembelajaran Bahasa Arab. Malang: UIN-Malang Press. 